\title{
Faux frogs: multimodal signalling and the value of robotics in animal behaviour
}

\author{
RYAN C. TAYLOR* $†$, BARRETT A. KLEIN†, JOEY STEIN‡ \& MICHAEL J. RYAN†§ \\ ${ }^{*}$ Science Department, Mount Saint Mary's University, Emmitsburg, MD \\ †Section of Integrative Biology, University of Texas at Austin \\ $\ddagger$ Moey Inc., Brooklyn, NY \\ $\S$ Smithsonian Tropical Research Institute, Balboa, Panama
}

Keywords: female choice; multimodal signalling; Physalaemus pustulosus; robotics; sexual selection; túngara frog; visual cue

\begin{abstract}
A long-standing interest in animal behaviour has been to understand chains of stimulus-response. One approach to understanding the links between stimulus and response has been to use models (animal replicas) in which details of a behaviour can be manipulated to determine how such manipulations influence the response of the focal animal. Static models (Tinbergen \& Perdeck 1950; Searcy 1998; McLister 2003), manually controlled robots (Brown \& Kiely 1974; Taylor et al. 2007) and motorized static models (MacLaren et al. 2004; Gumm et al. 2006) have been effective in eliciting responses from animals in behavioural studies. The current availability, however, of low-cost electric motors, easily designed circuit boards and a wide variety of sculpting materials has created even greater possibilities for developing robots as tools in studies of animal behaviour. In recent years a number of workers have capitalized on these technologies which are now increasingly being employed in controlled experiments (Knight 2005). In some research programmes, robots have been developed as a physical algorithm to test hypotheses about the mechanisms of behaviour (reviewed in: Webb 2000). In these studies, biological systems are modelled with robots and the behaviour of the robots is analysed in response to some stimulus input. Examples of these include studies of navigation (Lambrinos et al. 2000) and chemical trail following (Kuwana \& Shimoyama 1998; Grasso et al. 2000). Robotics have also been used as tools in studies where the robot interacts with living animals and it is this arena in which we are
\end{abstract}

Correspondence and present address: R. C. Taylor, Department of Biology, Salisbury University, 1101 Camden Ave, Salisbury, MD 21801, U.S.A. (email: rctaylor@salisbury.edu). B. A. Klein and M. J. Ryan are at the Section of Integrative Biology, University of Texas at Austin, Austin, TX 78712, U.S.A. J. Stein is at the Moey Inc., Brooklyn, NY 11215, U.S.A. particularly interested. Robotic technology has been used to test hypotheses regarding mate selection (robotic bowerbird: Patricelli et al. 2006), male-male territorial interactions (electromechanical model dart-poison frog: Narins et al. 2003, 2005), social aggregation (robotic brush-turkey chick: Göth \& Evans 2004; robotic cockroach: Halloy et al. 2007), predator avoidance (robotic ground squirrels: Rundus et al. 2007), communication of foraging locations (mechanical honeybee: Michelsen et al. 1989, 1992) and signal matching, territorial and sexual communication (robotic sagebrush lizard: Martins et al. 2005; Smith \& Martins 2006). The success of robotics in studies involving a wide variety of taxa indicates that this technology can provide an avenue for fruitful research in behaviour and communication.

Studies of communication are often conducted using acoustic playbacks (Martof 1961; Littlejohn \& Martin 1969; Gerhardt 1974; Gibson 1989), video animations (Rowland et al. 1995; Clark et al. 1997) or live animal manipulations (Andersson 1982; Basolo 1990; Morris et al. 2003). All of these methods have been effective, but here we wanted to explore the feasibility of using robotics in behavioural playback experiments, particularly with regard to multimodal signalling. With a need for greater control over realistic three-dimensional visual stimuli, synchronized with an acoustic signal, we developed a robotic frog to test the effects of multimodal signalling on mate selection and to assess the relative importance of specific visual components used during courtship in the túngara frog, Physalaemus pustulosus.

Auditory signals are a critical component of anuran amphibian communication and are important in mediating both female choice and male spacing within choruses (Ryan 2001; Gerhardt \& Huber 2002). A growing body of literature indicates, however, that visual cues are also an important component of communication in anuran breeding systems (Hödl \& Amézquita 2001). Although 
most studies of anuran visual signalling have been conducted with diurnal species (Summers et al. 1999; Narins et al. 2003), there is evidence that nocturnally active anurans show visual sensitivity under typical night-time illuminations (Larsen \& Pedersen 1982; Buchanan 1993; Cummings et al. 2008) and that visual signalling occurs in some nocturnal species (Amézquita \& Hödl 2004; Rosenthal et al. 2004; Taylor et al. 2007).

Túngara frogs are common throughout much of Middle America and their breeding coincides with the rainy season. They breed in a variety of habitats, ranging from the forest floor to forest edges as well as open, disturbed habitats. Like most frogs, they are nocturnal and use conspicuous vocalizations in their reproductive communication. The variably complex call of the túngara frog is a critical aspect of communication in this species and has been studied in detail (reviewed in: Ryan 1985; Ryan \& Rand 2003). During courtship, females assess calling males from distances of several centimetres before they initiate mating by making contact with the calling male. Under many conditions, such as bright moon and on cloudless nights, the male's vocal sac is a conspicuous cue to the human observer (Ryan 1985). Cummings et al. (2008) measured the visual sensitivity of túngara frogs under low-light conditions, showing that they see well at night. In addition to being visually sensitive at night, túngara frogs are responsive to the vocal sac as a visual cue, as shown in video playbacks (Rosenthal et al. 2004).

In this study we presented female túngara frogs with a realistic model of a calling male frog (hereafter referred to as a robotic or faux frog), in conjunction with synthesized male vocalizations, to test the hypothesis that females preferentially respond to a multimodal stimulus (auditory plus visual) over a unimodal stimulus (auditory only). In addition, we tested the hypothesis that visual subcomponents of our robotic frog differentially elicit a response from females. We also compared the outcome of the current study to results from a previous video playback study (Rosenthal et al. 2004) on female choice in túngara frogs and provide a discussion on the benefits and limitations of using robotics in playback studies. We also provide a detailed explanation of the mechanics of our robotic system because this level of description is missing in some studies that employ similar technologies.

\section{METHODS}

We conducted three experiments at the Smithsonian Tropical Research Institute in Gamboa, Panama during June and July of 2005 and 2006. In experiment 1, we tested the hypothesis that female túngara frogs preferentially respond to a multimodal stimulus. We conducted this experiment in an arena (ca. $1.8 \times 1.8 \mathrm{~m}$ ) made from a PVC frame with mattress foam suspended on the frame to form walls; acoustic ceiling tiles were placed on the outside of the foam walls of the arena to reduce reverberations. Within the arena, females were placed equidistant $(80 \mathrm{~cm})$ from two speakers such that the angle of the speakers relative to the female was approximately $50^{\circ}$ (Fig. 1). Each speaker broadcast the same, digitally synthesized male advertisement call antiphonally. Because we used the same call at each speaker, females were unable to make a choice based on differences in call properties. The call used was a complex call (whine plus chuck), which females do not discriminate from natural calls previously shown to be attractive to females (Rand et al. 1992).

Illumination for the arena was provided by a single GE brand night light (model no. 55507; Fairfield, CT, U.S.A.) suspended over the arena such that the full width of the arena received equal lighting coverage. The spectral output of our nightlight was green to the human eye, with a broad peak around $510 \mathrm{~nm}$. The natural spectrum of full moonlight is similar to sunlight (Johnsen et al. 2006). Endler (1993) characterized the spectra under daylight 'forest shade' as yellow-green and 'woodland shade' as bluish. Under clear, starlit skies, the spectrum is shifted to a series of narrow peaks above $560 \mathrm{~nm}$ (Johnsen et al. 2006). The 'forest shade' and 'woodland shade' habitats characterized by Endler (1993) are typical areas where túngara frogs breed, but they are also likely to be found in a variety of disturbed habitats where the spectrum may be very different. Because nocturnal spectra vary widely and túngara frogs are likely to experience different spectra depending on the particular habitat in which they are breeding, we made no attempt to match our experimental spectrum to a nocturnal spectral 'standard'. The spectrum in our arena, however, fell within the range of what túngara frogs experience in the field.

We placed duct tape over the majority of the light source, reducing output and rendering it similar to a typical nocturnal light level (arena irradiance $=5.85 \times$ $\left.10^{-10} \mathrm{~W} / \mathrm{cm}^{2}\right)$. Like the spectrum, the amount of

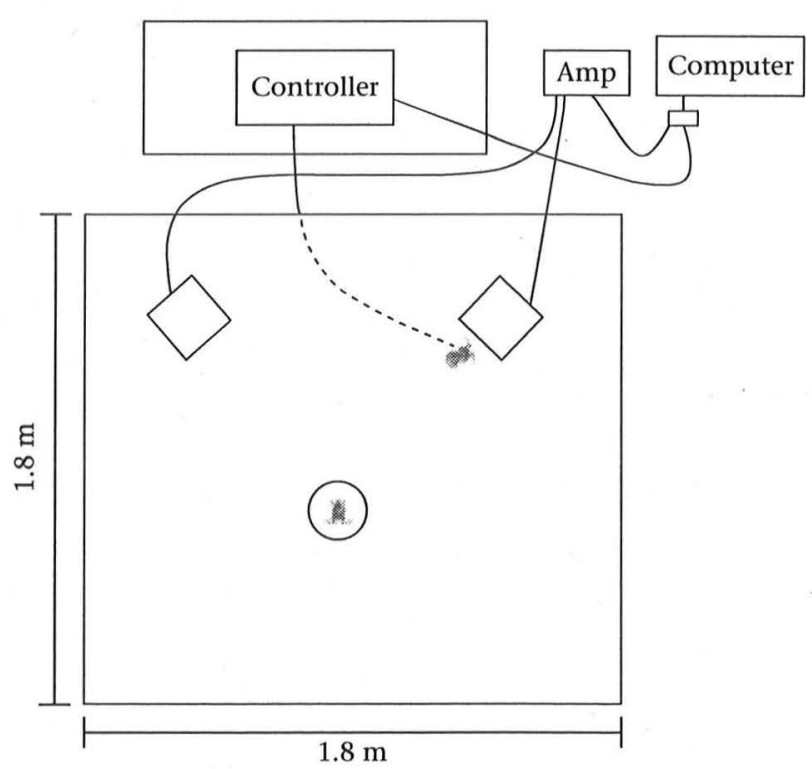

Figure 1. Schematic of test arena, including female release funnel (centre circle), speakers (two squares) and robotic male. Audio cables connect the computer to the amplifier (AMP) and the controller, and connect the amplifier to each speaker. Pneumatic tube (dotted line) transports air from the controller to the robotic male frog. The controller is housed within a box lined with acoustic ceiling tiles and acoustic foam to minimize sound output. 
nocturnal light also varies widely depending on moon phase, cloud cover and canopy cover; thus, no attempts were made to correlate light levels in our arena with a specific light level. Our radiance measures along the edge of a forest canopy, however, show that our experimental light levels were commensurate with values at the lower end of the range under which the frogs typically breed (outdoor irradiance range $=2.77 \times 10^{-9} \mathrm{~W} / \mathrm{cm}^{2}$ to $2.45 \times 10^{-7} \mathrm{~W} /$ $\mathrm{cm}^{2}$ ). All measurements were taken with an International Light IL 1700 research radiometer and PM271C photomultiplier detector, with the exception of the lower reading from the outdoor radiance range. This reading was taken using an International Light SHD033/W high-gain detector on an IL 1700. Readings from both detectors were similar except that the SHD033/W tended to yield slightly higher readings than the $\mathrm{PM} 271 \mathrm{C}$, probably because the SHD033/W has greater sensitivity in the infrared range.

Our visual stimulus was a fabricated robotic frog featuring an expandable vocal sac controlled distantly by an electromechanical unit (Fig. 2). A prototype of the robotic frog body was sculpted over a urethane cast (Smooth-Cast 305, Smooth-On, Easton, PA, U.S.A.) of a preserved frog specimen's body. Sculpted so that the body appeared inflated, the prototype was moulded and a urethane cast from this mould was fitted with hot-melt glue feet cast from a mould of the túngara frog specimen. The cast body was drilled/hollowed out from the vent to vocal sac region to accommodate insertion of an artificial vocal sac. To anchor the body to the arena's floor, two bolts (U.S. standard size $1-72 \times 1 / 2$ inches) were inserted and affixed with epoxy to ventrolateral points of the robotic frog body. Holes through the arena floor and below the model allowed passage of bolts anchoring the body, and for vocal sac tubing to exit the body through the vent region and remain hidden under the floor of the arena (Fig. 2b). The body of the robotic frog was painted with acrylics and oils and sealed with Krylon Crystal Clearcoat (Krylon Products Group, Cleveland,
OH, U.S.A.), sprayed over the model. The Clearcoat spray protected the fabricated body and added a realistic sheen.

A vocal sac consisted of latex, either cut from the neck of a balloon and tied via dental floss to one end of $1.58 \mathrm{~mm}$ PVC tubing (2005 season), or made from a silicone-coated or PTFE (Teflon)-coated, latex urological catheter (2006 season; Gold Foley catheter with $30 \mathrm{cc}$ balloon and 12 French diameter; Teleflex Medical, Rüsch Division, Research Triangle Park, NC, U.S.A.). To resemble real vocal sacs, pearlescent balloons were chosen, or catheter balloons were sprayed with a speckled coat of black automotive paint (Performix PLASTI DIP, Blaine, MN, U.S.A.). All vocal sacs featured a vertical white stripe, painted to match photographs of live specimens (Fig. 3). Stripes consisted of a white fabric paint (Jones Tones Glossy 3-D paint, Pueblo, CO, U.S.A.), or a 1:1 white acrylic paint and liquid latex mixture. Paint was applied to inflated vocal sacs $(10 \mathrm{cc})$ and inflated sacs were allowed to dry. Each artificial vocal sac ruptured after approximately $8 \mathrm{~min}$ of repeated inflations. This provided enough time to test two females per vocal sac. Our use of pre-painted balloons and catheters allowed us to change the vocal sacs quickly between trials.

Vocal sac inflations were controlled by a pneumatic system created from a $20 \mathrm{cc}$ plastic syringe, servo-motor, and fabricated plunger with a press fit rack attached to the plunger (Fig. 2a). The motor precisely turned a pinion to depress the syringe plunger and inflate an attached vocal sac. The controller of this system processed line-level audio input (designed for a computer headphone port) to trigger the pneumatic output. A sensitivity adjustment knob assured that the audio levels properly triggered the device.

For testing, we placed the robotic frog in front of one speaker, approximately $1 \mathrm{~cm}$ away from the front edge of the speaker; the other speaker lacked a robotic frog. The vocal sac of the faux frog was inflated synchronously with the call broadcast at the speaker, temporally (a)

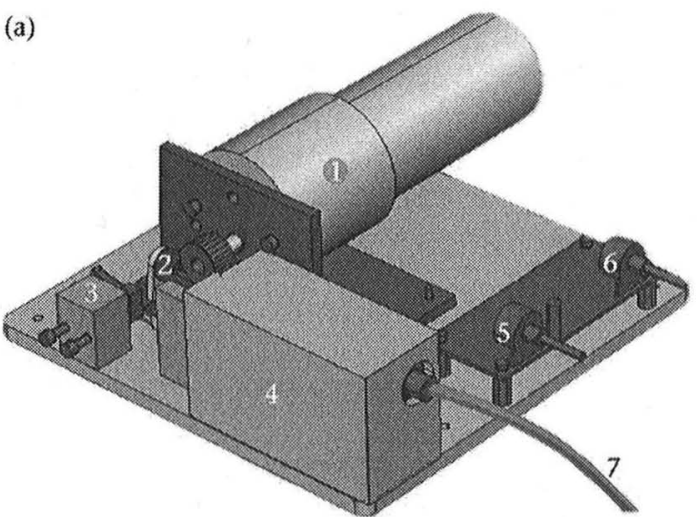

(b)

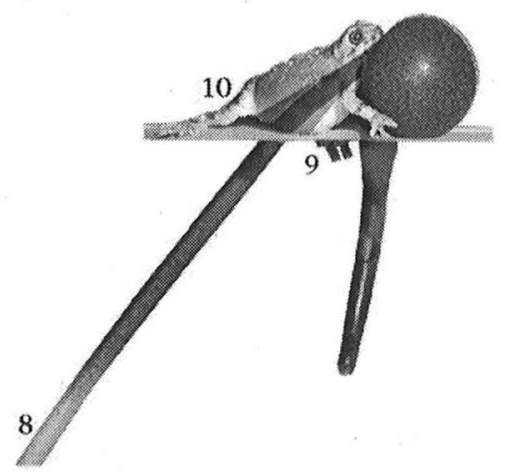

Figure 2. Robotic male frog and the mechanics controlling its vocal sac expansions. (a) Robotic frog controller. Pneumatic system in which the motor turns pinion to actuate the plunger and force air through the tubing leading to the model. (1) Servo Motor with built-in programmable controller. (2) Rack embedded into syringe plunger. (3) Homing and safety limit switches adjustable along slots. (4) $20 \mathrm{ml}$ syringe embedded in a block of milled Delrin. (5) Input sensitivity control. (6) Delay control. (7) PVC tubing through which air is expelled, leading to artificial vocal sac. (b) Robotic male frog with inflatable latex vocal sac. (8) Tubing connected to controller and inserted through model frog, exposing only artificial vocal sac above the substrate. Vocal sac: Silicone or PTFE-coated latex catheter (pictured), or latex balloon tied to PVC tubing, (9) Screws anchoring model. (10) Faux frog, with path of tubing made visible. 

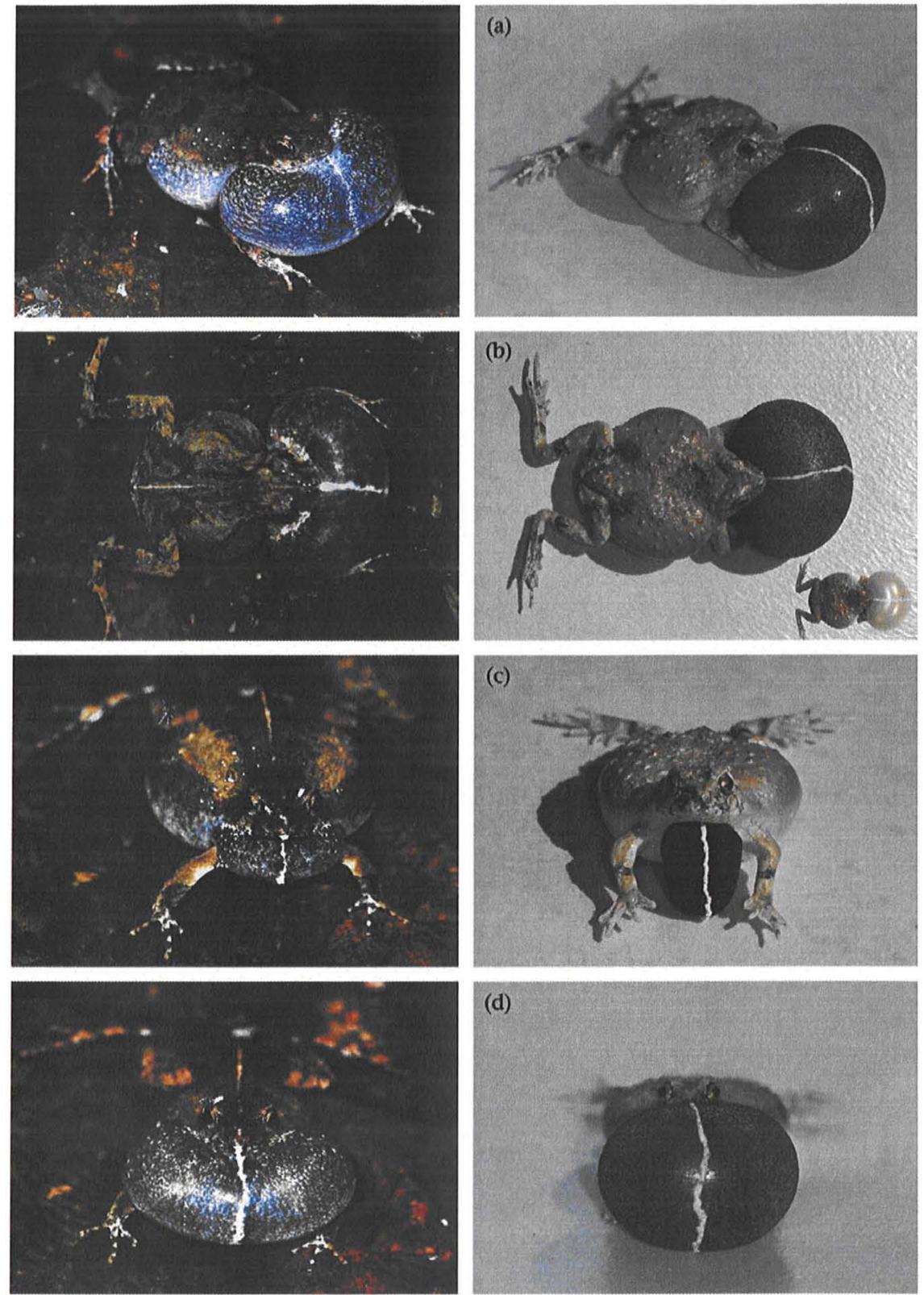

Figure 3. Photographs comparing real (left) and robotic (right) túngara frogs. Views: (a) lateral, (b) dorsal, (c) anterior with deflated vocal sac and (d) anterior with fully inflated vocal sac. Vocal sacs on all robotic frogs were part of a catheter except for the one inset in (b), which was a latex balloon.

mimicking the vocal sac inflation of a live calling male frog. The audio signal from the computer initiated inflation of the vocal sac by activating the controller servo-motor and depressing the plunger to force air into the vocal sac. Full inflation was achieved approximately $60 \%$ of the way through the call. Once full inflation was achieved, the controller motor reversed direction (retracting the plunger), pulling air from the vocal sac and deflating it. The deflation phase coincided with the final portion of the call broadcast at the speaker, and full deflation was achieved approximately $50 \mathrm{~ms}$ after the call. Although the deflation phase did not terminate precisely with the end of the call, in live males the deflation phase finishes slightly after the terminus of the call (personal. observation). Furthermore, the inflation/deflation sequence was sufficiently synchronized to elicit appropriate responses from females (R. C. Taylor, B. Stein, J. Stein \& M. J. Ryan, unpublished data).

Females for experiments were collected as amplectant pairs from the field around Gamboa, Panama. We placed individual pairs into plastic bags and placed them in a cooler in total darkness. We dark-adapted the frogs for 
a minimum of $1 \mathrm{~h}$ before testing (Cornell \& Hailman 1984; Fain et al. 2001). For testing, we removed a female from a male in a darkened room and placed her into the arena.

For each trial, we placed a female in the test arena under a funnel of transparent, polyethylene plastic food wrap. This funnel was largely transparent to both acoustic and visual signals. We initiated the playback from both speakers (and inflated the robotic frog at one speaker) and allowed the female to remain under the funnel for a minimum of $2 \mathrm{~min}$. Call amplitude was measured with a RadioShack no. 33-2050 sound level meter (fast RMS, C weighting; RadioShack Corp., Ft Worth, TX, U.S.A.) and set to $76 \mathrm{~dB}$ sound pressure level (SPL) (re. $20 \mu \mathrm{Pa}$ ). Prior to lifting the funnel and releasing the female, we required that she orient towards each speaker and speaker/robot combination so that she had the opportunity to gain visual information from both sources. In addition, we only released the female when she was oriented within a $15^{\circ}$ arc on either side of an axis dividing the middle of the chamber (female facing towards speakers). This minimized the possibility that the female's initial orientation would influence her choice. Once these criteria were met, we raised the funnel and released the female. We scored a choice when the female approached to within $5 \mathrm{~cm}$ of the robot or the speaker lacking the robot and remained there for $5 \mathrm{~s}$. After each trial we placed the robot in front of the other speaker and started the next trial with a new female. The robotic frog was consistently oriented in a manner such that its head was facing the female but angled approximately $30^{\circ}$ relative to the female (a frontal one-third view). This ensured that the female could see both the vocal sac and the lateral portion of the body of the robot (Fig. 1).

Experiments 2 and 3 were conducted in an identical manner as experiment 1 with the exception of the visual stimulus. In experiment 2 , we tested the hypothesis that the inflating vocal sac alone enhances the attractiveness of a call. Instead of using the robotic frog with an inflating vocal sac, we removed the robot body and presented females only with a vocal sac inflating synchronously with the call at the speaker. In experiment 3 , we tested the hypothesis that the visual stimulus of a nonmoving male enhances the attractiveness of a call. We presented females with a robot possessing a statically inflated vocal sac. No female was tested more than once in any experiment and females were not retested in separate experiments. After each night of testing, we returned all frogs to the location where they were captured.

\section{RESULTS}

In all experiments we predicted that visual cues would enhance the attractiveness of the acoustic signal (Narins et al. 2003; Rosenthal et al. 2004; Taylor et al. 2007), therefore we used one-tailed tests.

In experiment 1 , in which we presented females with a choice between a call only and a call coupled with a robotic frog in which the vocal sac inflation was synchronized with the call, females expressed a significant preference for the multimodal stimulus. Sixteen females responded to the call with the robotic frog and four females responded to the call only (binomial test: $P=0.006$ ). These results were statistically similar to the 14:6 bias shown by Rosenthal et al. (2004) using video models (Fisher's exact test: $P=0.716$; Fig. 4).

In experiment 2, 14 females chose the speaker with the inflating vocal sac (lacking the robotic frog body) and six chose the speaker without the inflating vocal sac (binomial test: $P=0.058$; Fig. 4). These results were not significantly different from the results in experiment 1 (Fisher's exact test: $P=0.92$ ).

In experiment 3 , seven females chose the speaker with the static robotic frog and 13 chose the speaker only (binomial test: $P=0.131$; Fig. 4). In summary, our results show that females prefer the audiovisual cue to just the audio cue, that the inflating vocal sac alone is enough to elicit a marginal preference for the multimodal signal, and that a static visual cue does not enhance the attractiveness of the acoustic signal.

\section{DISCUSSION}

Female túngara frogs expressed a significant preference for a robotic frog whose vocal sac inflation was synchronized with the advertisement call. Because we presented females with the same call at each speaker, this experiment showed that the visual stimulus of a calling male enhances the attractiveness of the advertisement call when females are unable to make distinctions among different calls.

In experiment 2 , females responded to the inflating vocal sac alone almost as strongly as they did when the body of the robotic frog was present. This response was similar to what was found using video playbacks as a visual stimulus (Rosenthal et al. 2004) and was not significantly different from responses to the entire robot. This finding suggests that the movement of the vocal sac is a salient component of the visual cue. Furthermore, it indicates

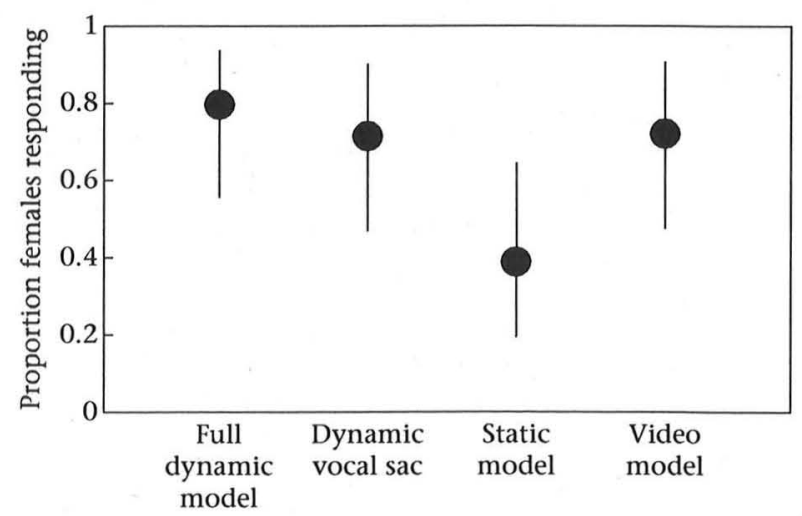

Figure 4. Proportion of females responding to a robotic model or video that was coupled with a digitized vocal call when the alternative was a speaker broadcasting the same call but lacking the visual stimulus of a model frog or video. Bars around the proportion represent $95 \%$ confidence intervals. Video data from Rosenthal et al. (2004). For all experiments $N=20$. 
that the modular nature of our robotic system was effective in ascertaining the important signal components.

Evidence that the dynamically inflating vocal sac is the primary cue used by females when making visual evaluations is further bolstered by our results from experiment 3 . In this experiment, females did not show a bias towards the side with the static robot. Our results indicate that a nonmoving visual stimulus does not enhance the attractiveness of the auditory signal, even when the visual stimulus is a highly realistic representation of a male frog. This result is not surprising given that nonmoving visual cues typically do not elicit responses from anuran amphibians (Lettvin et al. 1968; but see Vásquez \& Pfennig 2007). Our finding that the túngara frog vocal sac is the salient visual cue, stands in contrast to at least one other frog species where the vocal sac appears to be relatively unimportant (Taylor et al. 2007). These contrasting results suggest that the use of multimodal signals has diverged within anurans.

The experiments in this study support the finding by Rosenthal et al. (2004), using video playbacks, that female túngara frogs use visual cues and that the inflating vocal sac is salient for attraction. Rosenthal et al. (2004) presented females with vocalizations broadcast at $70 \mathrm{~dB}$ SPL to increase the probability that females would attend to the visual stimulus. In the present study we increased the call amplitude to $76 \mathrm{~dB}$ SPL, showing that females continue to attend to visual cues even at higher playback levels. Playbacks with túngara frogs are typically conducted at $82 \mathrm{~dB}$ SPL with the initial location of the female $1.35 \mathrm{~m}$ from the speaker (e.g. Ryan et al. 2003), which would be about $86.5 \mathrm{~dB}$ SPL at $80 \mathrm{~cm}$, the initial location of the female in our experiments. Calls of $76 \mathrm{~dB}$ SPL, however, are within the range of amplitudes that a female may experience in nature, and females in the laboratory respond to playbacks at even lower amplitudes (Marsh et al. 2000).

In natural choruses, male anurans often overlap their calls degrading the quality of the signals (Schwartz 1993) and rendering it difficult for females to distinguish among individual males (Gerhardt \& Klump 1988; Wollerman 1999). Acoustically distinguishing among individual calling males might present a special challenge for túngara frogs. Females perceptually group the whine and the chuck of a single call when these components are artificially separated by angles of up to $135^{\circ}$, effectively responding as if the two call components were produced at the same location (Farris et al. 2002, 2005). As such, females might have difficulty assigning a chuck to a particular male and need to rely on visual cues to supplement auditory discrimination among potential mates in large choruses. Under natural conditions, vegetation and heterogeneity of the substrate are likely to render only a subset of males in a chorus visible to females (personal observation). In those cases, males that are visually accessible to the females may increase their probability of being selected.

For studies of animal communication, video playbacks can be a powerful tool. They offer the ability to provide complex visual stimuli to animals without adding confounding variations (such as unwanted odours or substrate-borne vibrations) and they provide the experimenter with a potentially wider array of stimulus configurations than could be accomplished with liveanimal presentations (Rosenthal 1999). Despite this, there are several advantages of using robotic models over video playback. First, robots provide a three-dimensional representation of the visual stimulus. This ensures a more natural presentation, especially when test animals alter their position relative to the stimulus. Second, video playbacks have the potential to induce visual artefacts (e.g. pixilation, changes in temporal response, or chromatic shifts) that could lead to misinterpretations of the test animals' responses (D'Eath 1998; Fleishman \& Endler 2000; Trainor $\&$ Basolo 2000). For example, video screens were designed for human viewers, so the colour reproduction is a combination of three wavelengths ('red', 'blue', and 'green') dictated by a model of human colour perception given the specific sensitivities of our three cones. Animals with visual sensitivity in the UV range will perceive the colour output of video displays differently than a human viewer. Likewise, video screens (especially LCD's) were designed for viewing within a relatively narrow angle in front of the screen. An animal that moves around an experimental chamber is likely to view the screen at an extreme angle, altering its perception of colour and its perspective (D'Eath 1998; Fleishman \& Endler 2000). Rosenthal et al. (2004) controlled for some of these problems by restricting the movement of the female túngara frogs to a narrow angle in front of the stimulus. The use of the robots in this study eliminated the potential video problems and allowed females to move freely about the chamber during assessment. Should tactile information be necessary in future studies, a robot also offers possibilities unavailable with video playback.

Another advantage of using robotic models over video playbacks is that it allows for control of lighting between the sources of visual stimuli during experiments. In choice experiments, video may not present problems for diurnal species as ambient chamber light is likely to swamp out any subtle difference in brightness between video screens (but see D'Eath 1998 for discussion regarding flickerfusion frequency). For nocturnal species, the use of video screens could be a critical issue as the majority of light in the experimental arena is probably emitted from the screens. Many species of anurans show a photopositive response to light under low-illumination conditions (Jaeger \& Hailman 1981). Likewise, Rand et al. (1997) found that female choice in túngara frogs is influenced by ambient light levels. Thus, small differences in brightness between two video screens could potentially influence the animal's behaviour irrespective of the visual stimulus. The use of robots allows the experimenter to create an independent, overhead light source (as would occur in nature) and provides control over ambient light levels. In this study we adjusted both the spectrum and the intensity of the ambient light to be similar to those which túngara frogs are likely to experience under natural conditions.

Depending on the species and complexity of display, robotics may be more limited than video playback in presenting subtle nuances of complex visual displays to test subjects. The movements of a calling male frog are 
typically stereotyped and do not consist of a large repertoire of different motor patterns. With the exception of frog species that engage in foot-flagging behaviours (see Lindquist \& Hetherington 1996; Amézquita \& Hödl 2004), the most conspicuous visual display of calling male frogs is the vocal sac. Our robotic system captures the salient feature of the visual stimulus (the vocal sac) and provides the ability to control and manipulate light conditions independently of the visual stimulus.

The anuran vocal sac is synonymous with calling and is one of the more distinctive features of this order of animals. The vocal sac appears to have evolved primarily as a device to recirculate air during calling (de Jongh \& Gans 1969; Martin 1972; Gans 1973). This and related functions have been investigated in some detail in túngara frogs (Bucher et al. 1982; Dudley \& Rand 1991; Savitsky et al. 1999; Pauly et al. 2006). A number of studies have suggested that this original adaptive function has been co-opted to serve a second adaptive function, visual communication (Narins et al. 2003, 2005; Hirschman \& Hödl 2006). Although this secondary function of the vocal sac is not surprising in diurnal species, it is unexpected for animals that are nocturnally active. We refer to the vocal sac here as a cue rather than a signal since its primary function did not evolve for communication (see Bradbury \& Vehrencamp 1998). The vocal sac of many species is white or translucent, while in other species it is adorned with a variety of patterns of different hue and brightness, suggesting that these accoutrements may have evolved as visual signals.

An important aspect of understanding the evolution of multimodal signalling involves determining the context in which the signals are used. For example, the signal components may be redundant, conveying the same information, or nonredundant, conveying different information (Johnstone 1996; Martins et al. 2005; Partan \& Marler 2005). Because of spatial auditory grouping, it is likely that female túngara frogs have difficulty assigning the attractive chuck component to a specific male when multiple males are calling (Farris et al. 2002, 2005). The use of the vocal sac as a visual cue may increase a female's ability to assign a call to a particular male; thus, multimodal signalling in this system may have evolved as an efficacy trade-off (Hebets \& Papaj 2005), whereby the acoustic signal is detectable from a relatively long distance and the visual cue provides for better localization or discrimination by females. Our results provide additional evidence that anurans assess multimodal stimuli during courtship. Furthermore, our results with the robotic frogs suggest that this system will provide an excellent means of conducting additional studies to gain a better understanding of the evolution of multimodal communication.

\section{Acknowledgments}

We are grateful to Donald VanRoyen of Humanfactors Design Works in New York who served as mechanical engineer of the robotic frog controller. We thank Marc Gallo and Michael Schneider for electrical engineering expertise. We thank Bill Wcislo and Molly Cummings for providing the radiometers and spectrometers to take light measurements. Cathi Repetto (Teleflex Medical) supplied test samples of catheters. Karin Akre, Ximena Bernal, Kim Hoke, Alex Baugh and three anonymous referees provided valuable recommendations on this manuscript. Juanita Choo contributed useful vocal sac design advice and helped fabricate vocal sacs. The Smithsonian Tropical Research Institute provided logistical support. Funding was provided by National Science Foundation grant nos IBN 98-16564 and 0517328 to M.J.R. and R.C.T. This research complied with all requirements of the animal care and use protocols of the University of Texas; IACUC no. 4031701. All necessary permission and permits were obtained from the Smithsonian Tropical Research Institute and the government of Panama.

\section{References}

Amézquita, A. \& Hödl, W. 2004. How, when, and where to perform visual displays: the case of the Amazonian frog, Hyla parviceps. Herpetologica, 60, 420-429.

Andersson, M. 1982. Female choice selects for extreme tail length in a widowbird. Nature, 299, 818-820.

Basolo, A. 1990. Female preference for male sword length in the swordtail, Xiphophorus helleri (Pisces: Poeciliidae). Animal Behaviour, 40, 332-338.

Bradbury, J. W. \& Vehrencamp, S. L. 1998. Principles of Animal Communication. Sunderland, Massachusetts: Sinauer.

Brown, C. P. \& Kiely, P. C. 1974. The role of early experience and emotionality in social facilitation of pecking in chickens. Animal Behaviour, 22, 100-109.

Buchanan, B. W. 1993. Effects of enhanced lighting on the behaviour of nocturnal frogs. Animal Behaviour, 45, 893-899.

Bucher, T. L., Ryan, M. J. \& Bartholomew, G. A. 1982. Oxygen consumption during resting, calling, and nest building in the frog Physalaemus pustulosus. Physiological Zoology, 55, 10-22.

Clark, D. L., Macedonia, J. M. \& Rosenthal, G. G. 1997. Testing video playback to lizards in the field. Copeia, 1997, 421-423.

Cornell, E. A. \& Hailman, J. P. 1984. Pupillary responses of two Rana pipiens: complex anuran species. Herpetologica, 40, 356-366.

Cummings, M. E., Bernal, X. E., Reynaga, R., Rand, A. S. \& Ryan, M. J. 2008. Visual sensitivity to a conspicuous male cue varies by reproductive state in Physalaemus pustulosus females. Journal of Experimental Biology, 21, 1203-1210.

D'Eath, R. B. 1998. Can video images imitate real stimuli in animal behaviour experiments? Biological Reviews, 73, 267-292.

Dudley, R. \& Rand, A. S. 1991. Sound production and vocal sac inflation in the túngara frog, Physalaemus pustulosus (Leptodactylidae). Copeia, 1991, 460-470.

Endler, J. A. 1993. The color of light in forests and its implications. Ecological Monographs, 63, 1-27.

Fain, G. L., Matthews, H. R., Cornwall, M. C. \& Koutalos, Y. 2001. Adaptation in vertebrate photoreceptors. Physiological Reviews, 81, 117-151.

Farris, H. E., Rand, A. S. \& Ryan, M. J. 2002. The effects of spatially separated call components on phonotaxis in túngara frogs: evidence for auditory grouping. Brain, Behavior and Evolution, 60, 181-188.

Farris, H. E., Rand, A. S. \& Ryan, M. J. 2005. The effect of time, space and spectrum on auditory grouping in túngara frogs. Journal of Comparative Physiology, 191, 1173-1183.

Fleishman, L. J. \& Endler, J. A. 2000. Some comments on visual perception and the use of video playback in animal behavior studies. Acta Ethologica, 3, 15-27. 
Gans, C. 1973. Sound production in the Salientia: mechanism and evolution of the emitter. American Zoologist, 13, 1179-1194.

Gerhardt, H. C. 1974. The significance of some spectral features in mating call recognition in the green treefrog (Hyla cinerea). Journal of Experimental Biology, 61, 229-241.

Gerhardt, H. C. \& Huber, F. 2002. Acoustic Communication in Insects and Anurans: Common Problems and Diverse Solutions. Chicago: University of Chicago Press.

Gerhardt, H. C. \& Klump, G. M. 1988. Masking of acoustic signals by the chorus background noise in the green treefrog: a limitation on mate choice. Animal Behaviour, 36, 1247-1249.

Gibson, R. M. 1989. Field playback of male display attracts females in lek breeding sage grouse. Behavioral Ecology and Sociobiology, 24, 439-443.

Göth, A. \& Evans, C. S. 2004. Social responses without early experience: Australian brush-turkey chicks use specific visual cues to aggregate with conspecifics. Journal of Experimental Biology, 207, 2199-2208.

Grasso, F., Consi, T., Mountain, D. \& Atema, J. 2000. Biomimetic robot lobster performs chemo-orientation in turbulence using a pair of spatially separated sensors: progress and challenges. Robotics and Autonomous Systems, 30, 115-131.

Gumm, J. M., Gonzalez, R., Aspbury, A. S. \& Gabor, C. R. 2006. Do I know you? Species recognition operates within and between the sexes in a unisexual-bisexual species complex of mollies. Ethology, 112, 448-457.

Halloy, J., Sempo, G., Caprari, G., Rivault, C., Asadpour, M., Tâche, F., Said, I., Durier, V., Canonge, S., Amé, J. M., Detrain, C., Correll, N., Martinoli, A., Mondada, F., Siegwart, R. \& Deneubourg, J. L. 2007. Social integration of robots into groups of cockroaches to control self-organized choices. Science, 318, 1155-1158.

Hebets, E. A. \& Papaj, D. R. 2005. Complex signal function: developing a framework of testable hypotheses. Behavioral Ecology and Sociobiology, 57, 197-214.

Hirschman, W. \& Hödl, W. 2006. Visual signaling in Phrynobatrachus krefftii Boulenger, 1909 (Anura: Ranidae). Herpetologica, 62, 18-27.

Hödl, W. \& Amézquita, A. 2001. Visual signaling in anuran amphibians. In: Anuran Communication (Ed. by M. J. Ryan), pp. 121-141. Washington, D.C.: Smithsonian Institution Press.

Jaeger, R. G. \& Hailman, J. P. 1981. Activity of neotropical frogs in relation to ambient light. Biotropica, 13, 59-65.

de Jongh, H. J. \& Gans, C. 1969. On the mechanism of respiration in the bullfrog, Rana catesbiana: a reassessment. Journal of Morphology, 127, 259-290.

Johnsen, S., Kelber, A., Warrant, E., Sweeney, A. M., Widder, E. A., Lee, R. L., Jr \& Hernández-Andrés, J. 2006. Crepuscular and nocturnal illumination and its effects on color perception by the nocturnal hawkmoth Deilephila elpenor. Journal of Experimental Biology, 209, 789-800.

Johnstone, R. A. 1996. Multiple displays in animal communication: "backup signals" and "multiple messages". Philosophical Transactions of the Royal Society of London, Series B, 251, 329-338.

Knight, J. 2005. When robots go wild. Nature, 434, 954-955.

Kuwana, Y. \& Shimoyama, I. 1998. A pheromone-guided mobile robot that behaves like a silkworm moth with living antennae as pheromone sensors. International Journal of Robotics Research, 17, 924-933.

Lambrinos, D., Moller, R., Labhart, T., Pfeifer, R. \& Wehner, R. 2000. A mobile robot employing insect strategies for navigation. Robotics and Autonomous Systems, 30, 39-64.

Larsen, L. O. \& Pedersen, J. N. 1982. The snapping response of the toad, Bufo bufo, towards prey dummies at very low light intensities. Amphibia-Reptilia, 2, 321-327.
Lettvin, J. Y., Maturana, H. R., McCulloch, W. S. \& Pitts, W. H. 1968. What the frog's eye tells the frog's brain. In: The Mind: Biological Approaches to Its Functions (Ed. by W. C. Corning \& M. Balaban), pp. 233-258. New York: J. Wiley.

Lindquist, E. D. \& Hetherington, T. E. 1996. Field studies on visual and acoustic signaling in the "earless" Panamanian golden frog, Atelopus zeteki. Journal of Herpetology, 30, 347-354.

Littlejohn, M. J. \& Martin, A. A. 1969. Acoustic interaction between two species of leptodactylid frogs. Animal Behaviour, 17, 785-791.

MacLaren, R. D., Rowland, W. J. \& Morgan, N. 2004. Female preferences for sailfin and body size in the sailfin molly, Poecilia latipinna. Ethology, 110, 363-379.

McLister, J. D. 2003. The metabolic cost of amplexus in the grey tree frog (Hyla versicolor): assessing the energetics of male mating success. Canadian Journal of Zoology, 81, 388-394.

Marsh, D. M., Rand, A. S. \& Ryan, M. J. 2000. Effects of inter-pond distance on the breeding ecology of túngara frogs. Oecologia, 122, 505-513.

Martin, W. F. 1972. Evolution of vocalization in the genus Bufo. In: Evolution in the Genus Bufo (Ed. by W. F. Blair), pp. 279-309. Austin: University of Texas Press

Martins, E. P., Ord, T. J. \& Davenport, S. W. 2005. Combining motions into complex displays: playbacks with a robotic lizard. Behavioral Ecology and Sociobiology, 58, 351-360.

Martof, B. S. 1961. Vocalizations as an isolating mechanism in frogs. American Midland Naturalist, 65, 118-126.

Michelsen, A., Andersen, B. B., Kirchner, W. H. \& Lindauer, M. 1989. Honeybees can be recruited by a mechanical model of a dancing bee. Naturwissenschaften, 76, 277-280.

Michelsen, A., Andersen, B. B., Storm, J., Kirchner, W. H. \& Lindauer, M. 1992. How honeybees perceive communication dances, studied by means of a mechanical model. Behavioral Ecology and Sociobiology, 30, 143-150.

Morris, M. R., Nicoletto, P. F. \& Hesselman, E. 2003. A polymorphism in female preference for a polymorphic male trait in the swordtail Xiphophorus cortezi. Animal Behaviour, 65, 45-52.

Narins, P. M., Hödl, W. \& Grabul, D. S. 2003. Bimodal signal requisite for agonistic behavior in a dart-poison frog, Epipedobates femoralis. Proceedings of the National Academy of the Sciences, U.S.A., 100, 577-580.

Narins, P. M., Grabul, D. S., Soma, K. K., Gaucher, P. \& Hödl, W. 2005. Cross-modal integration in a dart-poison frog. Proceedings of the National Academy of the Sciences, U.S.A., 102, 2425-2429.

Partan, S. R. \& Marler, P. 2005. Issues in the classification of multimodal communication signals. American Naturalist, 166, 231-245.

Patricelli, G., Coleman, S. W. \& Borgia, G. 2006. Male satin bowerbirds (Ptilonorhynchus violaceus) adjust their display intensity in response to female startling: an experiment with robotic females. Animal Behaviour, 71, 49-59.

Pauly, G., Bernal, X., Rand, A. S. \& Ryan, M. J. 2006. The vocal sac increases call rate in the túngara frog Physalaemus pustulosus. Physiological and Biochemical Zoology, 79, 708-719.

Rand, A. S., Ryan, M. J. \& Wilczynski, W. 1992. Signal redundancy and receiver permissiveness in acoustic mate recognition by the túngara frog, Physalaemus pustulosus. American Zoologist, 32 81-90.

Rand, A. S., Bridarolli, M. E., Dries, L. \& Ryan, M. J. 1997. Light levels influence female choice in túngara frogs: predation risk assessment? Copeia, 1997, 447-450.

Rosenthal, G. G. 1999. Using video playback to study animal communication. Environmental Biology of Fishes, 56, 307-316.

Rosenthal, G. G., Rand, A. S. \& Ryan, M. J. 2004. The vocal sac as a visual cue in anuran communication: an experimental analysis using video playback. Animal Behaviour, 68, 55-58. 
Rowland, W. J., Bolyard, K. J. \& Halpern, A. D. 1995. The dual effect of stickleback nuptial coloration on rivals: manipulation of a graded signal using video playback. Animal Behaviour, 50, 267-272.

Rundus, A. S., Owings, D. H., Joshi, S. S., Chinn, E. \& Giannini, N. 2007. Ground squirrels use an infrared signal to deter rattlesnake predation. Proceedings of the National Academy of the Sciences, U.S.A., 104, 14372-14376.

Ryan, M. J. 1985. The Túngara Frog, a Study in Sexual Selection and Communication. Chicago: University of Chicago Press.

Ryan, M. J. (Ed.) 2001. Anuran Communication. Washington, D.C.: Smithsonian Institution Press.

Ryan, M. J. \& Rand, A. S. 2003. Mate recognition in túngara frogs: a review of some studies of brain, behavior, and evolution. Acta Zoologica Sinica, 49, 713-726.

Ryan, M. J., Rand, W., Hurd, P. L., Phelps, S. M. \& Rand, A. S. 2003. Generalization in response to mate recognition signals. American Naturalist, 161, 380-394.

Savitsky, A. H., Roberts, K. A. \& Rand, A. S. 1999. Organization of elastic fibers in the vocal sacs of frogs. American Zoologist, 39, 98A.

Schwartz, J. J. 1993. Male calling behavior, female discrimination and acoustic interference in the Neotropical treefrog Hyla microcephala under realistic acoustic conditions. Behavioral Ecology and Sociobiology, 32, 401-414.
Searcy, W. A. 1998. Do female red-winged blackbirds limit their own breeding densities? Ecology, 69, 85-95.

Smith, C. B. \& Martins, E. P. 2006. Display plasticity in response to a robotic lizard: signal matching or song sharing in lizards? Ethology, 112, 955-962.

Summers, K., Symula, R., Clough, M. \& Cronin, T. 1999. Visual mate choice in poison frogs. Proceedings of the Royal Society of London, Series B, 266, 1-5.

Taylor, R. C., Buchanan, B. W. \& Doherty, J. L. 2007. Sexual selection in the squirrel treefrog, Hyla squirella: the role of multimodal cue assessment in female choice. Animal Behaviour, 74, 1753-1763.

Tinbergen, N. \& Perdeck, A. C. 1950. On the stimulus releasing the begging response in the newly hatched herring gull chick (Larus argentatus Pont.). Behaviour, 3, 1-39.

Trainor, B. C. \& Basolo, A. L. 2000. An evaluation of video playback using Xiphophorus helleri. Animal Behaviour, 53, 83-89.

Vásquez, T. \& Pfennig, K. S. 2007. Looking on the bright side: females prefer coloration indicative of male size and condition in the sexually dichromatic spadefoot toad, Scaphiopus couchii. Behavioral Ecology and Sociobiology, 62, 127-135.

Webb, B. 2000. What does robotics offer animal behaviour? Animal Behaviour, 60, 545-558.

Wollerman, L. 1999. Acoustic interference limits call detection in a Neotropical frog, Hyla ebraccata. Animal Behaviour, 57, 529-536. 